\title{
CARACTERIZAÇÃO FÍSICO-QUÍMICA DA MUCILAGEM DE INHAME LIOFILIZADA
}

\author{
Physical and chemical characteristics of the mucilage of lyophilized yam \\ Sandra Aparecida Tavares ${ }^{1}$, Joelma Pereira$^{2}$, Mário César Guerreiro ${ }^{3}$, \\ Carlos José Pimenta ${ }^{2}$, Lucinéia Pereira ${ }^{3}$, Simone Velloso Missagia ${ }^{2}$
}

\begin{abstract}
RESUMO
A mucilagem do inhame desempenha papel de interesse na indústria de alimentos em razão das suas propriedades como espessante, estabilizante e emulsificante. Neste estudo, objetivou-se caracterizar a mucilagem liofilizada do inhame por meio de análises físicas, químicas e reológicas. Foram determinados a composição centesimal, valor calórico, pH, acidez, sais minerais, vitamina $\mathrm{C}$, açúcares totais, polifenóis, pectinametilesterase, poligalacturonase, termogravimétrica, análise térmica diferencial, calorimetria diferencial de varredura, espectroscopia infravermelho e viscosidade aparente. A mucilagem de inhame liofilizada apresentou elevados teores de proteína bruta e fibra alimentar e baixos teores de fração glicídica e de valor calórico. Quanto à análise termogravimétrica a mucilagem de inhame demonstrou maior perda de massa cerca de $60 \%$ à temperatura média de $200^{\circ} \mathrm{C}$, o que inviabiliza o seu uso acima desta temperatura.
\end{abstract}

Termos para indexação: Composição centesimal, reologia, termogravimétrica, fibra alimentar.

\section{ABSTRACT}

The mucilage of yam is of interest in the food industry due to its properties as a thickener, stabilizer and emulsifier. The aim of this study was to characterize the freeze-dried mucilage of yam through physical analysis, chemical and rheological properties. The study measured the proximate composition, caloric value, $\mathrm{pH}$, acidity, minerals, vitamin $\mathrm{C}$, sugars, polyphenols, pectin methylesterase, polygalacturonase, thermogravimetric, differential thermal analysis, differential scanning calorimetry, infrared spectroscopy and viscosity. The lyophilized yam mucilage showed high levels of crude protein and dietary fiber content and low fraction of glucose and calories. A thermogravimetric analysis mucilage of the yam showed a higher weight loss (about $60 \%$ ) at an average temperature of $200^{\circ} \mathrm{C}$, thus precluding their use above this temperature.

Index terms: Composition, rheology, thermogravimetry, dietary fiber.

\section{(Recebido em 30 de março de 2010 e aprovado em 24 de setembro de 2010)}

\section{INDRODUÇÃO}

O inhame é nativo de regiões dos hemisférios sob o clima tropical. É popular na África Ocidental e partes de Ásia, América do Sul e Central. Além de ser essa cultura ser paladar excelente, seus tubérculos são considerados nutritivos, contêm proteínas e são ricos em fibras e em minerais tais como o fósforo e o potássio, destacam-se ainda por apresentar, em sua constituição química, vitaminas do complexo $\mathrm{B}$.

Para fins industriais do inhame, a mucilagem contida no tubérculo representa papel de interesse. A mucilagem faz parte da composição da fibra que se encontra nesses tubérculos. Dessa forma, pode ser entendida como uma substância gomosa encontrada nos vegetais (COLACASIA, 2008). Do ponto de vista físico, ela é um sistema coloidal líquido, liofílico, sendo, portanto, um hidrogel; quimicamente, é constituída por água, pectinas, açúcares e ácidos orgânicos (MISAKI et al., 1972).

A mucilagem de inhame confere propriedades funcionais para produtos, tanto da indústria alimentícia como da indústria farmacêutica. As suas propriedades de viscosidade e de emulsão possibilitam ampla aplicação. A viscosidade de seu gel torna possível espessar e modificar a textura do alimento. Sendo aplicados em confecção de geléias, produtos de panificação, fabricação de diversos doces e nas indústrias farmacêuticas para correção de gostos dos fármacos e como estabilizador de emulsões e pomadas (HOU et al., 2002).

As características físico-químicas e térmicas da mucilagem de inhame estão diretamente envolvidas com as suas propriedades funcionais.

A forma mais prática de fazer uso industrial da mucilagem de inhame é na forma de pó. Existem várias

\footnotetext{
'Universidade Estadual Paulista “Júlio de Mesquita Filho"/UNESP - Departamento de Produção Animal - Fazenda Experimental Lageado - Cx. P. I237 18610-380 - Botucatu, SP - sandratavzoo@yahoo.com.br

¿Universidade Federal de Lavras/UFLA - Departamento de Ciência dos Alimentos/DCA - Lavras, MG

${ }^{3}$ Universidade Federal de Lavras/UFLA - Departamento de Química/DQI - Lavras, MG
}

Ciênc. agrotec., Lavras, v. 35, n. 5, p. 973 -979, set./out., 2011 
maneiras de desidratar a mucilagem e, uma delas, é utilizando processo de liofilização, esse processo mantém as mesmas características do inhame in natura. A fim de compreender mais a respeito desse novo produto foi desenvolvido o estudo de caracterização da Mucilagem de Inhame Liofilizada (MIL).

\section{MATERIAL E MÉTODOS}

\section{Matéria-prima e obtenção da mucilagem de inhame liofilizada (MIL)}

O inhame foi adquirido no comércio varejista de hortifrutigranjeiros. Cerca de 30 quilogramas do tubérculo foram lavados em água corrente, descascados e novamente lavados em água corrente. Porções de 300 gramas desse inhame foram triturados em liquidificador industrial por cinco minutos e, no final, todas as porções foram reunidas e homogenizada

A mucilagem foi extraída manualmente do inhame triturado por filtração em malha de poliéster $(40 \mathrm{cmx} 40 \mathrm{~cm})$. O filtrado (mucilagem) foi liofilizado para posterior realização das análises físico-químicas e análises térmicas.

A mucilagem filtrada foi liofilizada por aproximadamente 72 horas no aparelho Edwards, modelo L4KR, Série 163, Brasil e, ao final, foi obtido o produto mucilagem de inhame liofilizado.

\section{Rendimento da mucilagem de inhame liofilizada}

Os inhames foram pesados, descascados e triturados. A mucilagem de inhame foi extraída e submetida ao processo de liofilização. Em seguida, o material foi novamente pesado a fim de verificar o rendimento da mucilagem de inhame liofilizada - MIL.

\section{Análises da mucilagem de inhame liofilizada}

Umidade: de acordo com a metodologia $\mathrm{n}^{\circ} 925.09$ da AOAC (2000), até, obtenção do peso constante. Extrato etéreo: de acordo com a metodologia ${ }^{\circ} 925.38$ da AOAC (2000). Proteína bruta: de acordo com o método de microKjeldahl $n^{\circ} 920.87$ da AOAC (2000). Cinzas: de acordo com o método gravimétrico da AOAC, (2000) n 923.03, com calcinação a $550^{\circ} \mathrm{C}$, com permanência da amostra dentro da mufla-FORNITEC, modelo 1926, Brasil. Minerais: de acordo com a metodologia de Malavolta et al. (1997). Fibra alimentar: o valor de fibras totais foi calculado conforme a Equação 1, de acordo com a metodologia da AOAC (1995). O resultado foi expresso em g $100 \mathrm{~g}^{-1}$ de matéria integral.

Fibra alimentar $=$ peso do resíduo - (peso de proteína e peso das cinzas)
Fração glicídica (extrato não nitrogenado): o método utilizado foi por diferença como determina a AOAC (2000), segundo a Equação 2.

Fração glicídica $=100$ - (umidade+ extrato etéreo+ proteína+ fibra alimentar+ cinza)

Valor calórico: foram utilizados fatores de conversão de Atwater, conforme metodologia de Osborne; Voogt, (1978), em que $4 \mathrm{kcal} \mathrm{g}^{-1}$ para proteínas, e carboidratos e $9 \mathrm{kcal} \mathrm{g}^{-1}$ para lipídios. O resultado foi expresso em kcal $100^{-1}$, baseado na Equação 3:

$\mathrm{VC}=\left(\mathrm{g} 100 \mathrm{~g}^{-1}\right.$ proteína $\left.\mathrm{x} 4\right)+\left(\mathrm{g}_{100 \mathrm{~g}^{-1}}\right.$ extrato etéreo $\mathrm{x} 9)+\left(\mathrm{g} 100 \mathrm{~g}^{-1}\right.$ carboidratos $\left.\mathrm{x} 4\right)$

Açúcares totais: a determinação de açúcares foi realizada segundo o método de Somogy, adaptado por Nelson (1944). Amido: o amido foi extraído por hidrólise ácida, segundo técnica da AOAC (1990) e identificado pelo método de Somogy, modificado por Nelson (1944). Os resultados foram expressos em $\mathrm{g} 100 \mathrm{~g}^{-1}$ matéria seca.

$\mathrm{O}$ pH e a acidez titulável de acordo com a metodologia de Cecchi (2003). E para o resultado da análise de acidez titulável foi expresso em miliequivalente de $\mathrm{NaOH}$ por cem gramas da matéria integral, utilizandose a equação 4 :

Acidez titulável $=\{\mathrm{N}$ (volume $\mathrm{NaOH} \times 1.000) \times$

fator de correção x 100$\} / g$

Polifenóis: os fenólicos totais ou polifenóis foram extraídos, segundo Goldstein e Swain (1963), na quantificação foi utilizado o método de Folin-Denis, conforme recomendação da AOAC (1990). Pectinametilesterase: a atividade enzimática foi adaptada pela técnica de Vilas Boas, 1995. Poligalacturonase: a extração foi realizada de acordo com a metodologia de Buecher e Furmanski (1978) modificada por Vilas Boas, 1995. Vitamina C total: segundo Strohecker e Henning (1967) e a leitura foi realizada a $\lambda=520 \mathrm{~nm} \mathrm{em}$ espectrofotômetro Beckman 640 B, com sistema computadorizado.

A Viscosidade aparente: para a determinação foi utilizado o Analisador Rápido de Viscosidade (Rapid Viscosity Analyser- RVA, New Port Scientific Pty. Ltd., Sidney, Warriewood, Austrália, seguindo-se a metodologia de $n^{\circ} 162$ da IACST (1995). Espectroscopia na Região do Infravermelho (FTIR): os materiais foram analisados por espectroscopia na região do infravermelho com transformação de Fourier (FTIR), em um aparelho Digilab (1) Excalibur, série FTS 3000 (Estados Unidos) com detector 
DTGS, com faixa espectral de $400 \mathrm{~cm}^{-1}$ a $4000 \mathrm{~cm}^{-1}$ e resolução de $4 \mathrm{~cm}^{-1}$. As amostras foram analisadas por transmissão em pastilhas de $\mathrm{KBr}$ de $7 \mathrm{~mm}$ de diâmetro.

Termogravimetria (TG) e Análise Térmica Diferencial (DTA): a análise termogravimétrica e a análise térmica diferencial foram utilizadas para monitorar o perfil de estabilidade térmica do material. As análises foram realizadas com $8,7 \mathrm{mg}$ de mucilagem de inhame liofilizada, os quais foram colocados em cadinho de alumina, sob fluxo de $300 \mathrm{~mL} \mathrm{~min}^{-1}$ de ar sintético em um analisador termomecânico Shimadzu DTG - 60 AH, Japão. As amostras foram aquecidas de $30^{\circ} \mathrm{C} \mathrm{a} 600^{\circ} \mathrm{C}$ com taxa de aquecimento de $5^{\circ} \mathrm{C} \mathrm{min}^{-1}$.

Calorimetria Diferencial de Varredura (DSC): para a realização da análise de calorimetria diferencial de varredura foram utilizados cerca de dois a três mg de mucilagem de inhame liofilizada, os quais foram colocados em cadinho de alumínio herméticos e analisados em DSC Q200 TA Instruments, Estados Unidos com faixa de temperatura de $80^{\circ} \mathrm{C}$ a $200^{\circ} \mathrm{C}$, de acordo com a metodologia descrita por Zhang et al. (1997).

\section{Delineamento experimental e análise estatística}

O experimento considerou o delineamento inteiramente casualizado. Para caracterizar a mucilagem de inhame liofilizada foram tomadas cinco replicatas aleatórias, com as quais se determinaram as médias e os desvios padrão dos parâmetros analisados.

\section{RESULTADOS E DISCUSSÃO}

\section{Rendimento da mucilagem de inhame liofilizada}

Para esse experimento, foram utilizados $30 \mathrm{~kg}$ de tubérculos de inhame in natura. Depois de descascados, o peso total desses tubérculos foi de $21,542 \mathrm{~kg}$, apresentando, assim, um rendimento de $71,71 \%$ de polpa e $28,29 \%$ de casca.

O rendimento da mucilagem de inhame liofilizada em relação ao tubérculo de inhame foi de $6,84 \%$.

\section{Caracterização da mucilagem de inhame liofilizada}

Para a composição centesimal em base seca e o valor calórico da mucilagem de inhame liofilizada, os valores

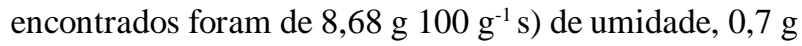

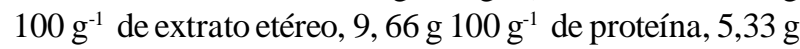

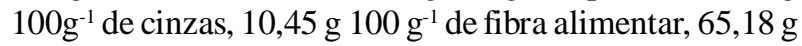
$100 \mathrm{~g}^{-1}$ de fração glicídica e valor calórico de 305,66 (kcal $\left.100 \mathrm{~g}^{-1}\right)$, valores esses superiores para umidade, proteína e cinza e inferior em relação ao valor calórico, quando comparado ao trabalho de Contado et al. (2009), também realizado com mucilagem de inhame liofilizada. A quantidade de fibra encontrada neste estudo foi significativa, e segundo Debiagi et al. (2010), as fibras podem ser usadas no reforço dos compostos. A adição das fibras não afeta o índice de expansão, mas diminui a solubilidade de água. A mucilagem, assim como o inhame, apresenta alto teor de minerais e dentre os macrominerais

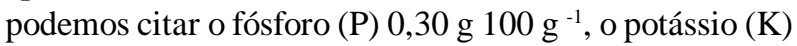
2,64 g $100 \mathrm{~g}^{-1}$, o cálcio (Ca) 0,13 g $100 \mathrm{~g}^{-1}$, o magnésio $(\mathrm{Mg})$

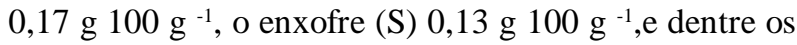
microminerais, o cobre $(\mathrm{Cu}) 16,45 \mathrm{mg} \mathrm{Kg}^{-1}$, o manganês (Mn) 27, $25 \mathrm{mg} \mathrm{Kg}^{-1}$, zinco (Zn) 14, $25 \mathrm{mg} \mathrm{Kg}^{-1}$ e o ferro (Fe) 41, $20 \mathrm{mg} \mathrm{Kg}^{-1}$. Os minerais que se apresentaram em maior quantidade em relação aos demais minerais foram o potássio (macromineral) e cobre (micromineral). Noinhame, o teor máximo de matéria seca é alcançado próximo da maturação fisiológica, enquanto que o teor máximo de proteínas ocorre bem antes do período de maturação. Dessa forma, pode se dizer que a composição centesimal varia conforme o estágio fisiológico dos tubérculos, segundo Brillouet et al. (1981) e Ketiku e Oyenuga (1973).

Os teores de açúcares da mucilagem de inhame liofilizados foram: açúcares totais de $3,65 \mathrm{~g} 100^{-1}$, de açúcares redutores de $1,4 \mathrm{~g} 100^{-1}$ e para açúcares não

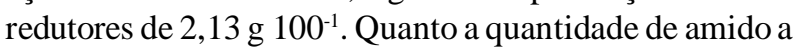

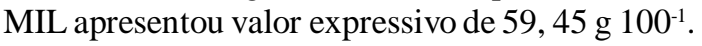

Em relação ao $\mathrm{pH}$ e à acidez titulável, a mucilagem de inhame liofilizada apresentou valores de 6,30 e de 7,48 $\mathrm{mEq} \mathrm{NaOH} 100 \mathrm{~g}^{-1}$ respectivamente. A concentração de íons hidrogênios é uma ferramenta importante, pois serve como medida de controle de qualidade. Produtos mais ácidos são, naturalmente, mais estáveis quanto à deterioração do que alimentos que apresentam $\mathrm{pH}$ próximo a neutralidade. No entanto, características intrínsecas tais como reduzido teor de umidade e consequentemente, baixa atividade de água apresentam baixo risco de desenvolvimento e crescimento de microrganismo. Fatores esses constantes na matriz alimentícia em estudo, mucilagem de inhame liofilizado.

Para polifenóis, o estudo em questão encontrou resultado de $278,52 \mathrm{mg} 100^{-1}$. No mesmo material, foi detectada a presença da enzima pectinametilesterase (PME). Já, atividade da enzima poligalaturonase (PG) não foi detectada. A essas pectinases são atribuídas à despolimerização de pectinas desesterificadas e altamente esterificadas, respectivamente.

Não foi encontrada a presença de vitamina $\mathrm{C}$ na mucilagem de inhame liofilizada, isso pode ser decorrente do processo de liofilização e o tempo de armazenamento, já que a vitamina $\mathrm{C}$ é muito lábil e fotossensível. 


\section{Viscosidade aparente}

O gráfico da viscosidade aparente da mucilagem de inhame liofilizada obtidos por RVA (Rapid Visco Analyser) está representado na Figura 1.

A viscosidade relativa da mucilagem de inhame liofilizada teve aumento brusco aos 3,33 minutos do início da análise a $17 \mathrm{cP}$, que pode ter sido causado pela rápida absorção de água, comportamento característico de material rico em fibra. A viscosidade máxima $3.354 \mathrm{cP}$ foi atingida a 4,13 minutos, a temperatura de $87,9^{\circ} \mathrm{C}$. A partir disso, como consequência da alta temperatura e da continuidade do trabalho mecânico, a viscosidade decresceu gradualmente, atingindo o máximo de $1.725 \mathrm{cP}$, aos 8,33 minutos, à temperatura $81,85^{\circ} \mathrm{C}$.
Ao final da análise, aos 13 minutos, quando a temperatura atingiu $49,95^{\circ} \mathrm{C}$, a viscosidade da MIL aumentou, chegando a $2.435 \mathrm{cP}$.

\section{Espectroscopia na região do infravermelho}

Os espectros FTIR da mucilagem de inhame liofilizada estão mostrados na Figura 2. Abanda $3.400 \mathrm{~cm}^{-1}$ a $3.300 \mathrm{~cm}^{-1}$ pode ser atribuída ao estiramento vibracional do grupo O-H de água e alcoóis. As absorções localizadas na região de $2.950 \mathrm{~cm}^{-1}$ até $2.800 \mathrm{~cm}^{-1}$ são características de vibrações simétricas e assimétricas de grupos $\mathrm{C}$-H metilas e metilenos. A absorção situada em $1.680 \mathrm{~cm}^{-1}$ a $1.630 \mathrm{~cm}^{-1}$ é característica de estiramento vibracional de $\mathrm{C}=\mathrm{O}$ de carbonila e ou compostos aromáticos.

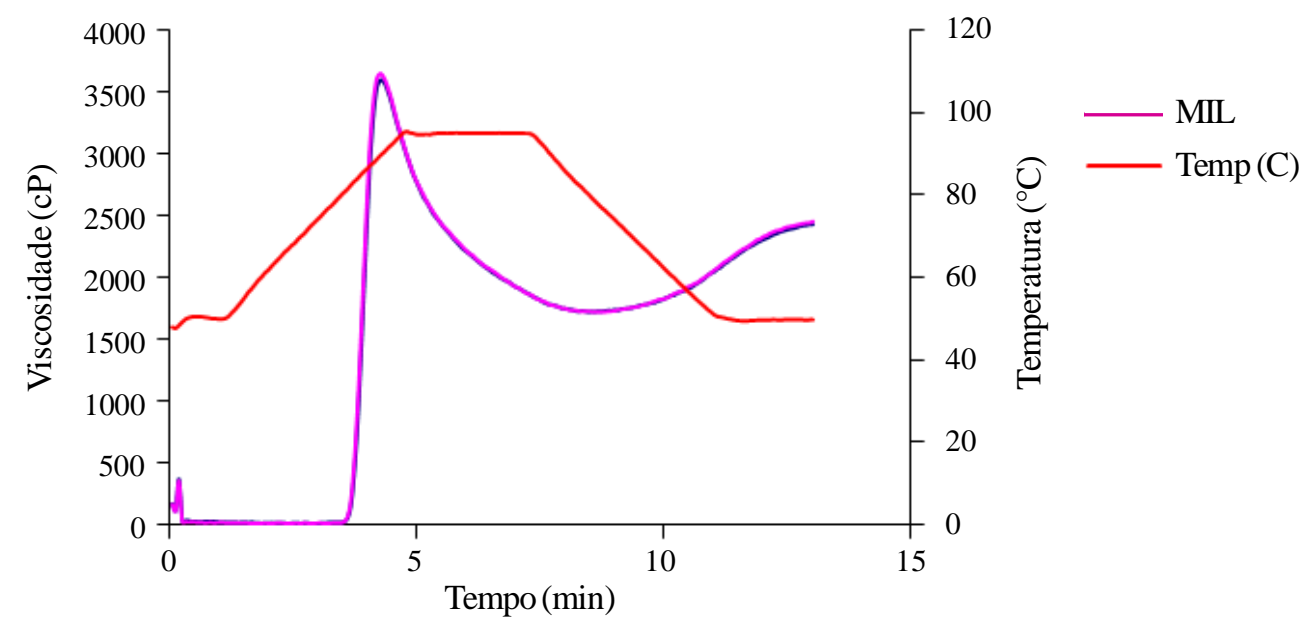

Figura 1 - Viscosidade aparente da mucilagem de inhame liofilizada obtida em RVA.

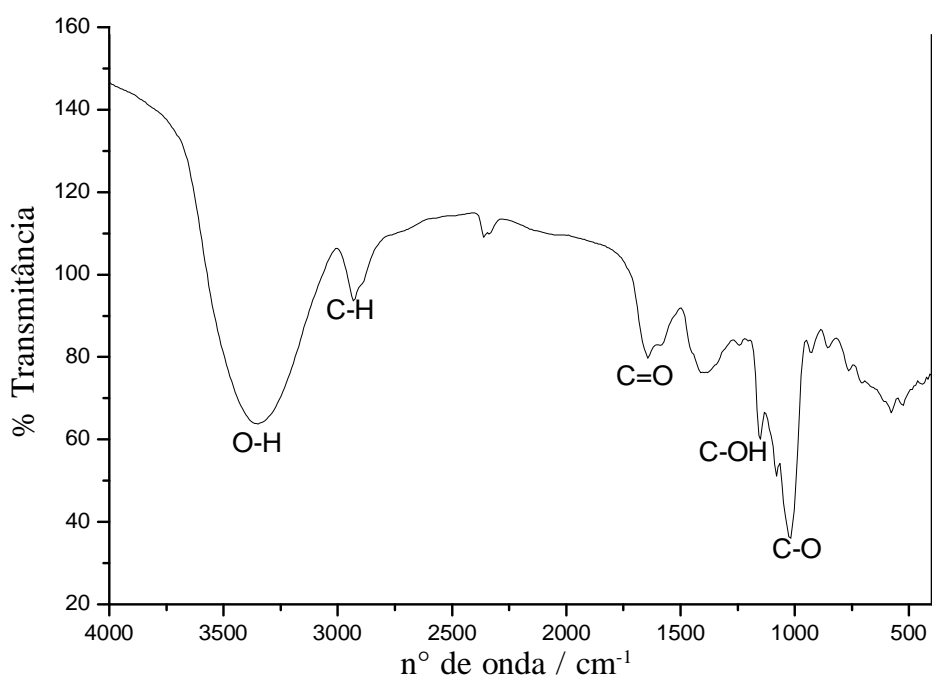

Figura 2 - Espectros FTIR da mucilagem de inhame liofilizada.

Ciênc. agrotec., Lavras, v. 35, n. 5, p. 973 -979, set./out., 2011 
No intervalo de $1.050 \mathrm{~cm}^{-1}$ a $1.150 \mathrm{~cm}-{ }^{1}$ observa-se um sinal largo que pode ser atribuído às deformações simétricas e assimétricas do grupo $\mathrm{C}-\mathrm{OH}$.

As bandas $900 \mathrm{~cm}^{-1} \mathrm{e} 1300 \mathrm{~cm}^{-1}$ são referentes ao estiramento vibracional C-O das ligações de álcoóis que ocorrem em $1.205 \mathrm{~cm}^{-1}$ a $1.120 \mathrm{~cm}^{-1}$.

\section{Análise térmica diferencial e Termogravimétrica}

O gráfico da análise Térmica Diferencial (DTA) e Termogravimétrica (TG) está representado na Figura 3.

Para TG, observou-se que a primeira perda de massa do material ocorreu na temperatura próximo a $100^{\circ} \mathrm{C}$, nessa primeira perda de média de $10 \%$ pode ter havido perda de água e compostos voláteis. A segunda perda ocorre na temperatura média de $200^{\circ} \mathrm{C}$, teve-se uma perda de massa acentuada, cerca de $60 \%$, posteriormente o material perdeu massa até a sua completa decomposição à temperatura acima de $500^{\circ} \mathrm{C}$, anterior a essa temperatura, à $450^{\circ} \mathrm{C}$, observou-se um fenômeno físico-químico típico desse material. Esse fenômeno ocorreu, pois houve rápida perda de massa com processo endotérmico acentuado, mais rápido que a resposta do equipamento aparecendo um ruído no termograma.

Para DTA, por volta de $250^{\circ} \mathrm{C}$, houve uma reação endotérmica do material mucilagem de inhame liofilizada. Em temperatura de $450^{\circ} \mathrm{C}$, ocorreu outro evento fortemente endotérmico com a mucilagem de inhame liofilizada.

\section{Calorimetria diferencial de varredura}

O gráfico da análise calorimetria diferencial de varredura (DSC), da mucilagem de inhame liofilizada esta representado na Figura 4.

Conforme visto na Figura 4, a fusão cristalina, (Tm) do material mucilagem de inhame liofilizada ocorreu à temperatura de $79,68^{\circ} \mathrm{C}$. Nessa temperatura, segmentos rígidos se desagregam e fundem. Tm é a temperatura na qual as cadeias poliméricas saem de sua estrutura cristalina, tornando-se um líquido sem ordem estabelecida.

Na fusão cristalina do material, ocorreu uma curva de aquecimento de processo endotérmico.

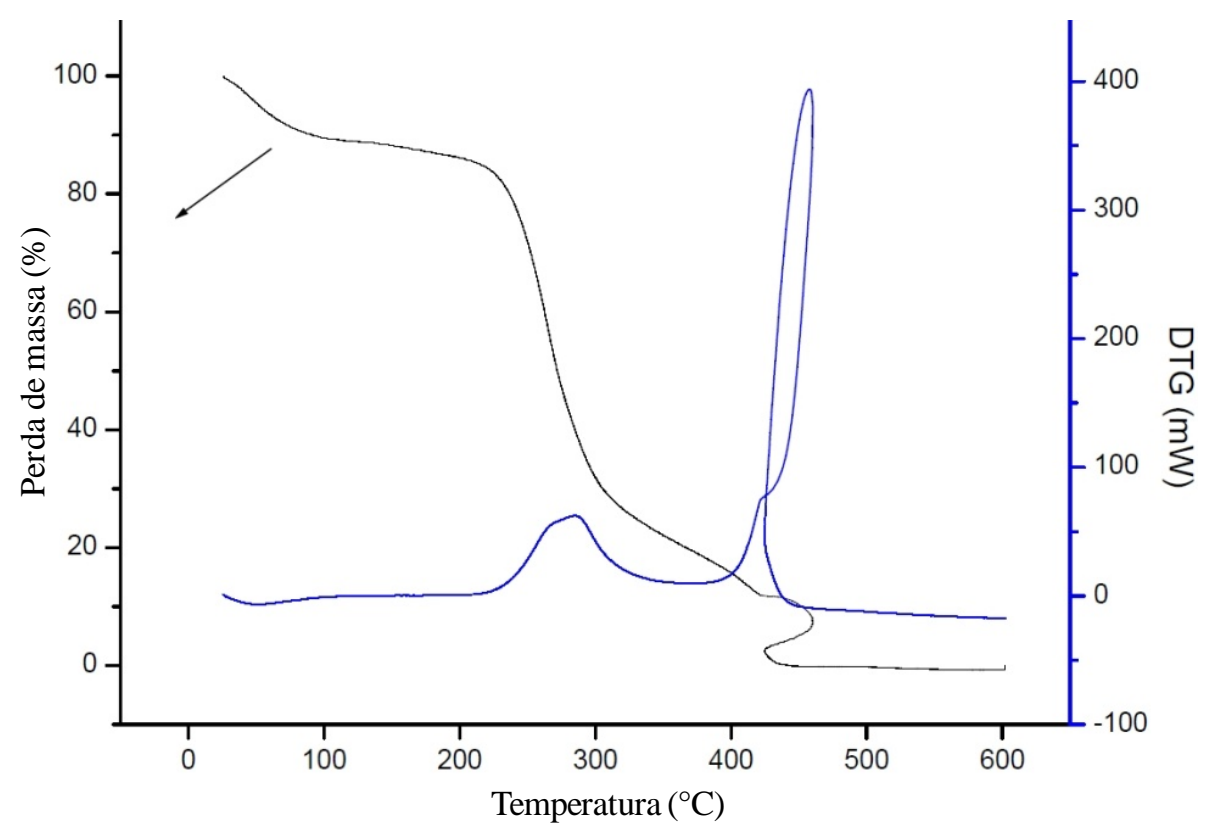

Figura 3 - Comportamento da mucilagem de inhame liofilizada sob análise térmica diferencial e termográfica. 


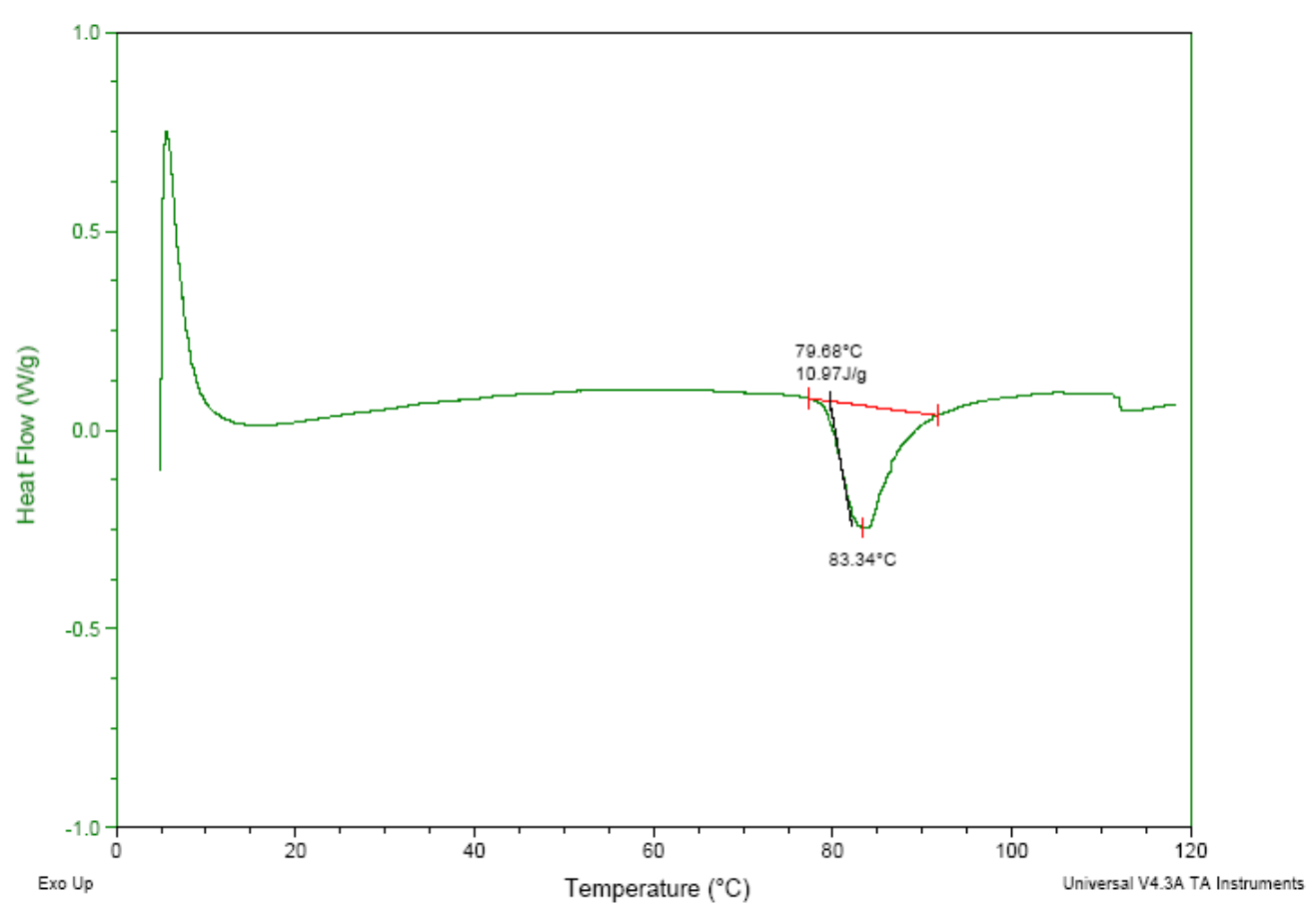

Figura 4 - Comportamento da mucilagem de inhame liofilizada sob a calorimetria diferencial de varredura.

\section{CONCLUSÕES}

Nas condições experimentais em que foi realizado o presente trabalho, os resultados obtidos permitiram concluir que:

- A mucilagem de inhame liofilizada apresenta elevados teores de proteína bruta, fibra alimentar, amido e minerais principalmente potássio e cobre e baixos teores de fração glicídica e valor calórico e ínfimo teor de polifenóis.

- Os valores de pH e acidez titulável encontrados na MIL estão numa faixa que não oferecem risco para a deterioração do produto.

- Não foi detectada a presença da enzima poligalaturonase (PG), porém foi detectada atividade na enzima pectinametilesterase (PME) na MIL.

- Em relação ao seu comportamento, no que diz a respeito especificamente à análise de termogravimétrica, a MIL demonstra maior perda de massa cerca de $60 \%$ à temperatura média de $200^{\circ} \mathrm{C}$, o que inviabiliza o seu uso acima dessa temperatura.

\section{AGRADECIMENTOS}

À FAPEMIG, CAPES e CNPq. À Embrapa Agroindústria de Alimentos, na pessoa do pesquisador Carlos Wanderlei Willer de Carvalho.

\section{REFERÊNCIASBIBLIOGRÁFICAS}

ASSOCIATIONOFOFFICIALAGRICULTURALCHEMISTS. Official methods of the Association of the Agricultural Chemists. 17. ed. Washington, DC, 2000. v.2, 1175.

ASSOCIATION OF OFFICIALAGRICULTURAL CHEMISTS. Official methods of the Association of the Agricultural Chemists. 16. ed. Washington, DC, 1995. v. 2, $1094 \mathrm{p}$.

ASSOCIATION OF OFFICIALAGRICULTURAL CHEMISTS. Official methods of the Association of the Agricultural Chemists. 15. ed. Washington, DC, 1990. v. $2,1298 \mathrm{p}$.

BRILLOUET, J. M.; TRECHE, S.; SEALY, L. Alterations in cell wall constituintes of yams Dioscorea dumetorum and $D$. rontuladata with maturation and storage conditions, relation with post harvest hardening of $D$. dumentorum yam tubers. Journal of Food Science, Chicago, v. 46, n. 6, p. 1964-1967, Nov./Dec. 1981.

BUESCHER, R. W.; FURMANSKI, R. J. Role of pectinesterase and polygalacturonase in the formation of wooliness in peaches. Journal of Food Science, Chicago, v. 43, n. 1, p. 18-22, 1978. 
CECCHI, H. M. Fundamentos teóricos e práticos em análise de alimentos. 2.ed. Campinas: Unicamp, 2003.

COLACASIA esculenta inhame-selvagem. Disponível em: <http://www.plantamed.com.br>. Acesso em: 15 dez. 2008.

CONTADO, E. W. et al. Composição centesimal da mucilagem do inhame (Dioscorea spp.) liofilizado comparado a de um melhorador comercial utilizado na panificação e avaliação sensorial de pães de forma. Ciência e Agrotecnologia, Lavras, v. 33, Edição Especial, p. 1813 -1818, 2009. Comunicação.

DEBIAGI, F. et al. Efeito de fibras vegetais nas propriedades de compósitos biodegradáveis de amido de mandioca produzidos via extrusão. Ciência e Agrotecnologia, Lavras, v. 34, n. 6, p. 1522-1529, nov./ dez., 2010.

GOLDSTEIN, J. L.; SWAIN, T. Changes in tannins in ripening fruits. Phytochemistry, Oxford, v. 2, p. 371-383, 1963.

HOU, W. C.; HSU, F. L.; LEE, M. H. Yam (Dioscorea batatas) tuber mucilage exhibited antioxidant activities in vitro. Planta Medica, Stuttgart, v. 68, n. 12, p. 10721076, Dec. 2002.

INTERNATIONALASSOCIATION FOR CEREAL SCIENCEAND TECHNOLOGY. Official methods of the International Association of Cereal Science and Technology. Schwechiat, 1995. 1 CD-ROM.

KETIKU, A. O.; OYENUGA, Y. A. Changes in the carbohydrate constituints of yam tuber (Dioscorea rotundata pois.) during growth. Journal of the Science of Food and Agricultural, London, v. 24, n. 4, p. 367-373, Apr. 1973.

MALAVOLTA, E.; VITTI, G. C.; OLIVEIRA, S. A. Avaliação do estado nutricional das plantas: princípios e aplicações. Piracicaba: Potafos, 1997.319 p.

MISAKI, A.; ITO, T.; HARADA, T. Constitutional Studies on the Mucilage of "Yamanoimo" Dioscorea batatas Decne, forma Tsukune: isolation and structure of a mannan. Agricultural and Biological Chemistry, Bethesda, v. 36, n. 5, p. 761-771, 1972.

NELSON, N. A. A photometric adaptation of Somogy method for the determination of glucose. Journal of Biology Chemistry, Baltimore, v. 153, n. 2, p. 375-380, May 1944.

OSBORNE, D. R.; VOOGT, P. The analysis of nutrient in foods. London: Academic, 1978. 158 p.

\section{STROHECKER, R.; HENNING, H. M. Análises de} vitaminas: métodos comprobados. Madrid: Paz Montalvo, 1967. 428 p.

VILAS BOAS, E. V. de B.; CHITARRA, A. B.; CHITARRA, M. I. F. Modificações pós-colheita de banana 'Prata' g- irradiada. Pesquisa Agropecuária Brasileira, Brasília, v.31, n.9, p.599-607, Set 1966.

ZHANG, Y. P.; LEWIS, R. N. A. H.; MCELHANEY, R. N. Calorimetric and spectroscopic studies of the thermotropic phase behavior of the $n$-saturated 1,2diacylphosphatidylglycerols. Biophysical Journal, Bethesda, v. 72, n. 2, p. 779-793, Feb. 1997. 